\title{
Green fluorescence of terbium ions in lithium fluoroborate glasses for fibre lasers and display devices
}

\author{
G R DILLIP ${ }^{1,6}$, C MADHUKAR REDDY ${ }^{2,6}$, M RAJESH ${ }^{3}$, SHIVANAND CHAURASIA ${ }^{4}$, \\ B DEVA PRASAD RAJU ${ }^{3,5, *}$ and $\mathrm{S}$ W JOO ${ }^{1}$ \\ ${ }^{1}$ School of Mechanical Engineering, Yeungnam University, Gyeongsan 712749 , South Korea \\ ${ }^{2}$ Department of Physics, AP Model School, Yerravaripalem 517 194, India \\ ${ }^{3}$ Department of Physics, Sri Venkateswara University, Tirupati 517 502, India \\ ${ }^{4}$ High Pressure \& Synchrotron Radiation Physics Division, Bhabha Atomic Research Centre, Mumbai 400 085, India \\ ${ }^{5}$ Department of Future Studies, Sri Venkateswara University, Tirupati 517 502, India
}

MS received 22 July 2015; accepted 6 December 2015

\begin{abstract}
In this paper, for the first time, the visible fluorescence properties, resonance energy transfer mechanism responsible for non-radiative decay rates of ${ }^{5} D_{4} \rightarrow{ }^{7} F_{5}$ transition and also quenching of fluorescence intensity of the ${ }^{5} D_{3} \rightarrow{ }^{7} F_{5}$ transition of various concentrations of $T^{3+}$ ions in LBZLFB glasses are reported. Optical absorption, fluorescence spectra and quantum efficiencies are measured and analysed. Green fluorescence related to ${ }^{5} \mathbf{D}_{4} \rightarrow{ }^{7} \mathbf{F}_{5}$ $(548 \mathrm{~nm})$ transition is registered under excitation of $378 \mathrm{~nm}$ of $\mathrm{Tb}^{3+}$ ions. Based on excitation and fluorescence measurements, several spectroscopic parameters for $\mathbf{T b}^{3+}$ ions are examined as a function of concentration by Judd-Ofelt theory to judge the suitability of studied glasses for display devices and fibre lasers.
\end{abstract}

Keywords. Glasses; terbium ion; oscillator strengths; fluorescence; lifetimes; fibre lasers.

\section{Introduction}

Today glasses are most favourable engineering materials for abundant applications due to the wide ability of property altering by compositional modifications. The considerable examination of glass science to achieve required properties is due to innovative role of glasses in optical communication and solid-state lasers attracted remarkable attention in the last few decades. Host phonon energy is one of such intrinsic property of glass which plays key role in favouring the luminescence performance of active ions. Low phonon energy glasses doped with rare earth (RE) ions are attractive materials for photonic devices. A great attention of research has been focused on RE ions-doped glasses owing to their wide ranging applications in laser and optical communication devices. Fluoride glasses in comparison with typical silica glasses used in fibre optic telecommunication are characterized by low attenuation of radiation significantly wider range of wavelength $(2000-7000 \mathrm{~nm})$ [1]. The oxyfluoroborate glasses are promising candidates for laser host materials due to their high transparency, chemical durability and thermal stability and large RE ion solubility. The intensities of the transitions for RE ions are evaluated using the procedure based on the Judd-Ofelt (J-O) theory [2,3]. A comparable

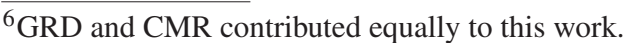

*Author for correspondence (drdevaprasadraju@ gmail.com)
}

knowledge on the fundamental data that includes optical efficiency, transition positions, transition probabilities, radiative and non-radiative decay rates, branching ratios, etc. to optimize the best configuration of the ion-host to improve the laser efficiency of a specific electronic transition. The hostdependent $\mathrm{J}-\mathrm{O}$ parameters have been used to obtain abovementioned radiative properties for the excited states and are very essential to estimate/design optical devices such as lasers, colour displays, upconverters, optical fibres and optical amplifiers and so on.

Glasses as laser hosts have advantages to form fibres more easily than single crystals and RE ions-doped glass fibre lasers have been applied in optical communication, optical fibre sensing, displays, medical treatment, etc. However, in the last decades, green fibre lasers was mainly achieved by using $\mathrm{Er}^{3+}$-doped glass fibres by upconversion luminescence process $[4,5]$. The green-pulsed laser operation based on ${ }^{5} \mathrm{D}_{4} \rightarrow{ }^{7} \mathrm{~F}_{5}$ transition of $\mathrm{Tb}^{3+}$ was first reported in 1967 [6]. Recently, Yamashita and Ohisi [8] reported green laser from $\mathrm{Tb}^{3+}$ ions-doped fluoride glass fibres pumped by $488 \mathrm{~nm}$ laser diode [7,8]. In this investigation, we select borate glass as the host for $\mathrm{Tb}^{3+}$ ions for display devices and to realize green fibre lasers. Absorption spectra and concentration dependent emission spectra, quantum efficiencies of the $\mathrm{Tb}^{3+}$ ions-doped borate glasses were measured. The spectroscopic properties of borate glasses containing high $\mathrm{Tb}^{3+}$ ion concentration may make them promising as materials for green fibre laser and solid-state materials. 


\section{Experimental}

The LBZLFB glasses used in this work were prepared with the composition in $\mathrm{mol} \% 20 \mathrm{PbO}+5 \mathrm{BaO}+5 \mathrm{ZnO}+10 \mathrm{LiF}$ $+(60-x) \mathrm{B}_{2} \mathrm{O}_{3}+x \mathrm{~Tb}_{2} \mathrm{O}_{3}$ (where $x=0.1,0.5,1.0,1.5$ and $2.0 \mathrm{~mol} \%)$. Each $10 \mathrm{~g}$ mixtures of reagent grade (99.9\%), $\mathrm{Pb}_{3} \mathrm{O}_{4}, \mathrm{BaCO}_{3}, \mathrm{ZnO}, \mathrm{LiF}, \mathrm{H}_{3} \mathrm{BO}_{3}$ and $\mathrm{Tb}_{2} \mathrm{O}_{3}$ chemicals were heated at $950^{\circ} \mathrm{C}$ for $1 \mathrm{~h}$ in an electric furnace using porcelain crucible. The melt was poured in a pre-heated brass cast and pressed with another brass plate to get a flat glass of $0.3 \mathrm{~cm}$ thick and then annealed at $300^{\circ} \mathrm{C}$ for $5 \mathrm{~h}$ to remove thermal strains. The obtained glasses were polished for measuring their physical and optical properties. Densities of glass samples were measured at room temperature (RT) with distilled water as the immersion liquid by the conventional Archimedes's principle. Abbe's refractometer was used to obtain the refractive indices for all the glass samples at sodium wavelength using 1-bromonaphthalene as the contact liquid. The various measured and calculated physical properties of the $1.0 \mathrm{~mol} \% \mathrm{~Tb}^{3+}$-doped LBZLFB glass are presented in table 1 . The absorption spectra were recorded using a double beam Perkin Elmer Lambda 950 spectrophotometer in the wavelength range of $250-2500 \mathrm{~nm}$. The excitation, emission and lifetime measurements were carried out using Jobin Yvon Fluorolog-3 spectrofluorometer with xenon flash lamp as source. All the measurements were carried out at RT.

\section{Results and discussion}

\subsection{Optical absorption spectra}

Figures 1 and 2 represent the RT absorption spectra of $1.0 \mathrm{~mol} \% \mathrm{~Tb}^{3+}$ ions-doped LBZLFB glass in the visible and near-infrared region, respectively. The absorption spectra consist a total of four bands at 486, 1891, 1954 and $2177 \mathrm{~nm}$ corresponding to the ${ }^{7} \mathrm{~F}_{6} \rightarrow{ }^{5} \mathrm{D}_{4},{ }^{7} \mathrm{~F}_{\mathrm{J}}=1-3$ transitions, respectively, and are assigned according to the energy level

Table 1. Measured and calculated physical properties for $1.0 \mathrm{~mol} \% \mathrm{~Tb}^{3+}$-doped LBZLFB glass.

\begin{tabular}{lr}
\hline Physical quantities & LBZLFB \\
\hline Sample thickness $(\mathrm{cm})$ & 0.300 \\
Refractive index $(n)$ & 1.580 \\
Density $\left(\mathrm{g} \mathrm{cm}^{-3}\right)$ & 4.960 \\
Concentration $\left(\mathrm{mol} \mathrm{l}^{-1}\right)$ & 0.256 \\
Concentration $\left(\right.$ ions $\left.\mathrm{cm}^{-3} \times 10^{20}\right)$ & 1.542 \\
Average molecular weight $(\mathrm{g})$ & 193.770 \\
Dielectric constant $(\varepsilon)$ & 2.496 \\
Molar volume, $V_{\mathrm{m}}\left(\mathrm{cm}^{3} \mathrm{~mol}^{-1}\right)$ & 39.060 \\
Glass molar refractivity $\left(\mathrm{cm}^{-3}\right)$ & 12.990 \\
Electronic polarizability, $\alpha_{\mathrm{e}}\left(\times 10^{-24} \mathrm{~cm}^{3}\right)$ & 5.150 \\
Reflection losses, $R(\%)$ & 5.053 \\
Polaron radius, $r_{\mathrm{p}}(\AA)$ & 7.514 \\
Inter ionic distance, $r_{\mathrm{i}}(\AA)$ & 18.648 \\
Field strength, $F\left(\times 10^{14} \mathrm{~cm}^{-2}\right)$ & 5.300 \\
\hline
\end{tabular}

positions of $\mathrm{Tb}^{3+}$ ions in the literature [9]. The spectral intensities for the observed bands in the absorption spectra are expressed in terms of oscillator strengths and are analysed with the help of Judd-Ofelt $(\mathrm{J}-\mathrm{O})$ theory using the procedure available in the literature [10-13]. The experimental oscillator strength $\left(f_{\exp }\right)$ and calculated oscillator strength $\left(f_{\text {cal }}\right)$ values along with assignment of absorption bands are tabulated in table 2. The goodness of the fit is obtained in terms of root mean square deviation $\left(\delta_{\mathrm{rms}}\right)$. As shown in the table, the obtained $\delta_{\text {rms }}$ deviation of $\pm 0.16 \times 10^{-6}$ is well consistent with the $f_{\text {exp }}$ and $f_{\text {cal }}$ values and also the validity of $\mathrm{J}-\mathrm{O}$ intensity parameters.

In the $1.0 \mathrm{~mol} \%$ LBZLFB glass, the evaluated set of $\mathrm{J}-\mathrm{O}$ intensity parameters: $\Omega_{2}=16.34 \times 10^{-20} \mathrm{~cm}^{2}, \Omega_{4}=0.25$ $\times 10^{-20} \mathrm{~cm}^{2}$ and $\Omega_{6}=5.74 \times 10^{-20} \mathrm{~cm}^{2}$ follow the trend $\Omega_{2}>\Omega_{6}>\Omega_{4}$. These parameters play an important role

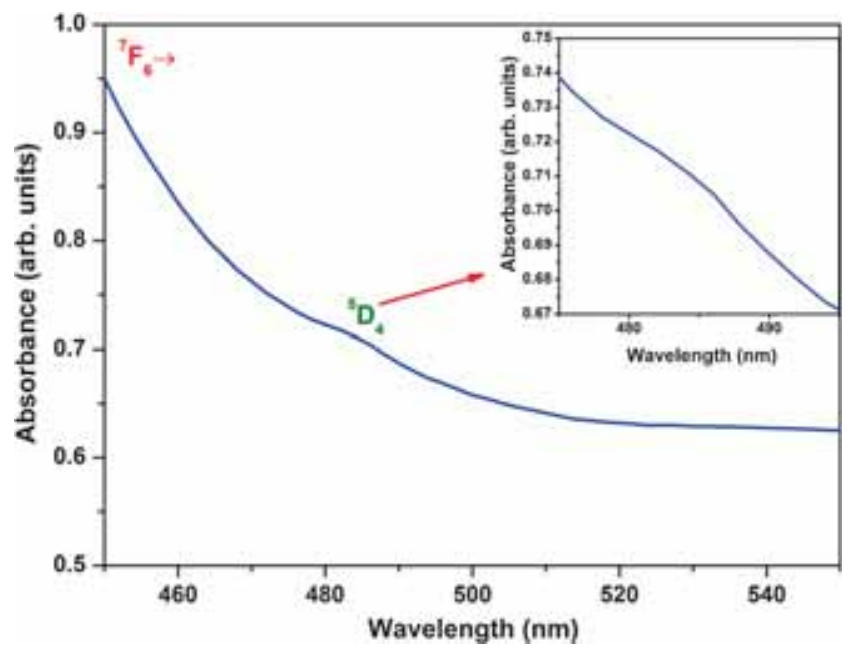

Figure 1. Vis absorption spectrum of $1.0 \mathrm{~mol} \% \mathrm{~Tb}^{3+}$-doped LBZLFB glass.

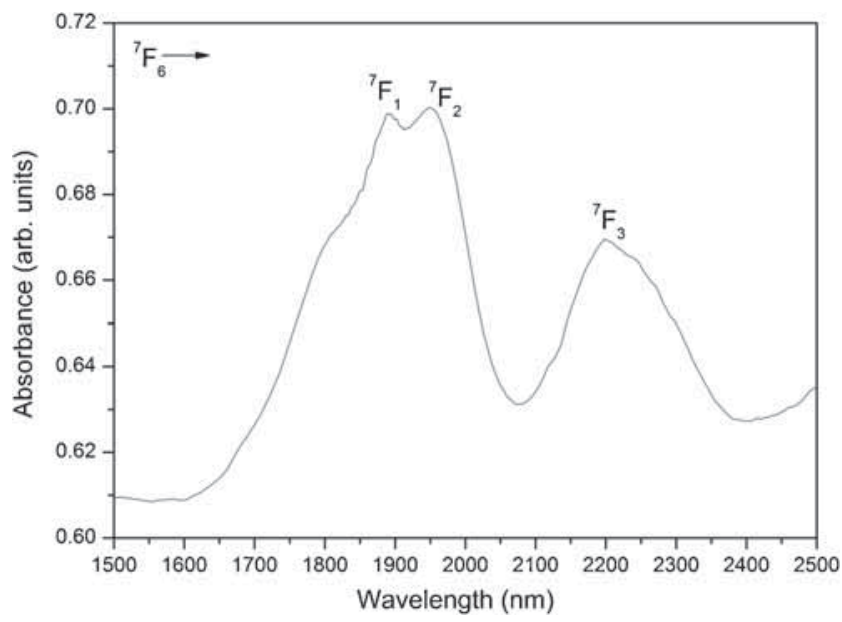

Figure 2. NIR absorption spectrum of $1.0 \mathrm{~mol} \% \mathrm{~Tb}^{3+}$-doped LBZLFB glass. 
to investigate the coordination environment as well as bonding in the vicinity of RE ions. $\Omega_{2}$ parameter is sensitive to the local environment and often attributed to the degree of covalence between the dopant ion and surrounding ligand, also it depends mainly on the asymmetry of the coordination structure and bonding nature $[14,15]$. The higher magnitude of $\Omega_{2}$ parameter is an indication of higher covalency of the dopant ion-ligand bonds and lower symmetry around RE ion. Moreover, the $\Omega_{4}$ and $\Omega_{6}$ parameters are less sensitive to the medium and related to the bulk properties such as viscosity and rigidity. The $\mathrm{J}-\mathrm{O}$ intensity parameters of $\mathrm{Tb}^{3+}$ ions doped different hosts are listed in table 3. From the table, it is clear that the $\Omega_{2}$ parameter varies significantly in different hosts. The $\Omega_{2}$ parameter of $1.0 \mathrm{~mol} \% \mathrm{~Tb}^{3+}$ ionsdoped LBZLFB glass is found to be higher to those reported in the literature. When compared to the other hosts $[13,16-$ 20], the sites occupied by $\mathrm{Tb}^{3+}$ ions in LBZLFB glasses possess lower symmetry and greater degree of covalence for $\mathrm{Tb}-\mathrm{O}$ bond. On the observation of intensity parameters, better luminescence properties may be expected in the present glasses than the reported glasses [13,16-20].

\subsection{Analysis of emission intensity}

The excitation spectrum shown in figure 3 was measured by monitoring the green emission $(548 \mathrm{~nm})$ of $\mathrm{Tb}^{3+}$ ion. The observed sharp bands at 353, 370, 378 and $486 \mathrm{~nm}$ corresponding to the ${ }^{7} \mathrm{~F}_{6} \rightarrow{ }^{5} \mathrm{~L}_{9},{ }^{5} \mathrm{~L}_{10},{ }^{5} \mathrm{G}_{6}$ and ${ }^{5} \mathrm{D}_{4}$ transitions, respectively. These bands are due to the $4 f-4 f$ transitions of $\mathrm{Tb}^{3+}$ ions [21]. To produce stronger emission and to study

Table 2. Experimental and calculated oscillator strengths $\left(\times 10^{-6}\right)$ for $1.0 \mathrm{~mol} \% \mathrm{~Tb}^{3+}$-doped LBZLFB glass.

\begin{tabular}{lccc}
\hline Transition $\left({ }^{7} \mathrm{~F}_{6} \rightarrow\right)$ & Energy $\left(\mathrm{cm}^{-1}\right)$ & $f_{\text {exp }}$ & $f_{\text {cal }}$ \\
\hline${ }^{5} \mathrm{D}_{4}$ & 20661 & 0.10 & 0.10 \\
${ }^{7} \mathrm{~F}_{1}$ & 5291 & 1.59 & 1.35 \\
${ }^{7} \mathrm{~F}_{2}$ & 5118 & 1.42 & 1.64 \\
${ }^{7} \mathrm{~F}_{3}$ & 4545 & 1.35 & 1.31 \\
& & \multicolumn{2}{c}{$\delta_{\text {rms }}= \pm 0.16 \times 10^{-6}$} \\
\hline
\end{tabular}

Table 3. Comparison of J-O intensity parameters $\left(\times 10^{-20} \mathrm{~cm}^{2}\right)$ and their trends for $\mathrm{Tb}^{3+}$ ions in LBZLFB glass with different glass hosts.

\begin{tabular}{lcccc}
\hline Glass system & $\Omega_{2}$ & $\Omega_{4}$ & $\Omega_{6}$ & Trend \\
\hline LBZLFB (present work) & 16.34 & 0.25 & 5.74 & $\Omega_{2}>\Omega_{6}>\Omega_{4}$ \\
$\mathrm{LiNO}_{3}-\mathrm{KNO}_{3}$ [20] & 15.00 & 2.86 & 5.24 & $\Omega_{2}>\Omega_{6}>\Omega_{4}$ \\
$\mathrm{PbO}-\mathrm{CaO}-\mathrm{ZnO}-\mathrm{NaF}-\mathrm{B}_{2} \mathrm{O}_{3}$ & 14.54 & 0.17 & 4.09 & $\Omega_{2}>\Omega_{6}>\Omega_{4}$ \\
$\quad[13]$ & & & & \\
$\mathrm{BaF}_{2}-\mathrm{ThF}_{4}-\mathrm{ZnF}_{2}-\mathrm{LiF}[18]$ & 13.40 & 2.15 & 4.90 & $\Omega_{2}>\Omega_{6}>\Omega_{4}$ \\
$\mathrm{KF}_{-} \mathrm{B}_{2} \mathrm{O}_{3}[19]$ & 11.92 & 0.26 & 2.16 & $\Omega_{2}>\Omega_{6}>\Omega_{4}$ \\
$\mathrm{PbF}_{2}-\mathrm{B}_{2} \mathrm{O}_{3}-\mathrm{Al}_{2} \mathrm{O}_{3}[16]$ & 8.20 & 1.95 & 3.31 & $\Omega_{2}>\Omega_{6}>\Omega_{4}$ \\
$\mathrm{CaO}_{-} \mathrm{B}_{2} \mathrm{O}_{3}[17]$ & 6.95 & 1.28 & 2.91 & $\Omega_{2}>\Omega_{6}>\Omega_{4}$ \\
$\mathrm{Na}_{2} \mathrm{O}-\mathrm{P}_{2} \mathrm{O}_{5}-\mathrm{Al}_{2} \mathrm{O}_{3}[17]$ & 6.80 & 1.11 & 2.27 & $\Omega_{2}>\Omega_{6}>\Omega_{4}$ \\
$\mathrm{Li}_{2} \mathrm{O}-\mathrm{B}_{2} \mathrm{O}_{3}[17]$ & 5.56 & 1.33 & 3.22 & $\Omega_{2}>\Omega_{6}>\Omega_{4}$ \\
\hline
\end{tabular}

the luminescence behaviour of $\mathrm{Tb}^{3+}$ ions in the present glass host, the excitation wavelength of $378 \mathrm{~nm}$ is used to record emission spectra. The emission spectra recorded for different concentrations of $\mathrm{Tb}^{3+}$ ions-doped glasses have similar profiles except in intensity, shown in figure 4 . The emission spectra comprise of several peaks both from ${ }^{5} \mathrm{D}_{3}$ and ${ }^{5} \mathrm{D}_{4}$ emission states. The luminescence below $480 \mathrm{~nm}$ originates from ${ }^{5} \mathrm{D}_{3}$ excited state, and above $480 \mathrm{~nm}$ originates from ${ }^{5} \mathrm{D}_{4}$ excited state. The peaks originating from the ${ }^{5} \mathrm{D}_{3}$ state are located at 418, 441 and $458 \mathrm{~nm}$ assigned to the ${ }^{5} \mathrm{D}_{3} \rightarrow$ ${ }^{7} \mathrm{~F}_{5},{ }^{7} \mathrm{~F}_{4}$ and ${ }^{7} \mathrm{~F}_{3}$ transitions, respectively, and while the peaks originating from the ${ }^{5} \mathrm{D}_{4}$ metastable state are located at 491, 548, 589 and $624 \mathrm{~nm}$ assigned to the ${ }^{5} \mathrm{D}_{4} \rightarrow{ }^{7} \mathrm{~F}_{6},{ }^{7} \mathrm{~F}_{5},{ }^{7} \mathrm{~F}_{4}$ and ${ }^{7} \mathrm{~F}_{3}$ transitions, respectively. Among these transitions, the bands corresponding to the ${ }^{5} \mathrm{D}_{3} \rightarrow{ }^{7} \mathrm{~F}_{5},{ }^{7} \mathrm{~F}_{4}$ and ${ }^{7} \mathrm{~F}_{3}$ and ${ }^{5} \mathrm{D}_{4} \rightarrow{ }^{7} \mathrm{~F}_{4}$ and ${ }^{7} \mathrm{~F}_{3}$ transitions are found to be very weak. The transitions related to the ${ }^{5} \mathrm{D}_{4} \rightarrow{ }^{7} \mathrm{~F}_{6}$ and ${ }^{7} \mathrm{~F}_{5}$ transitions

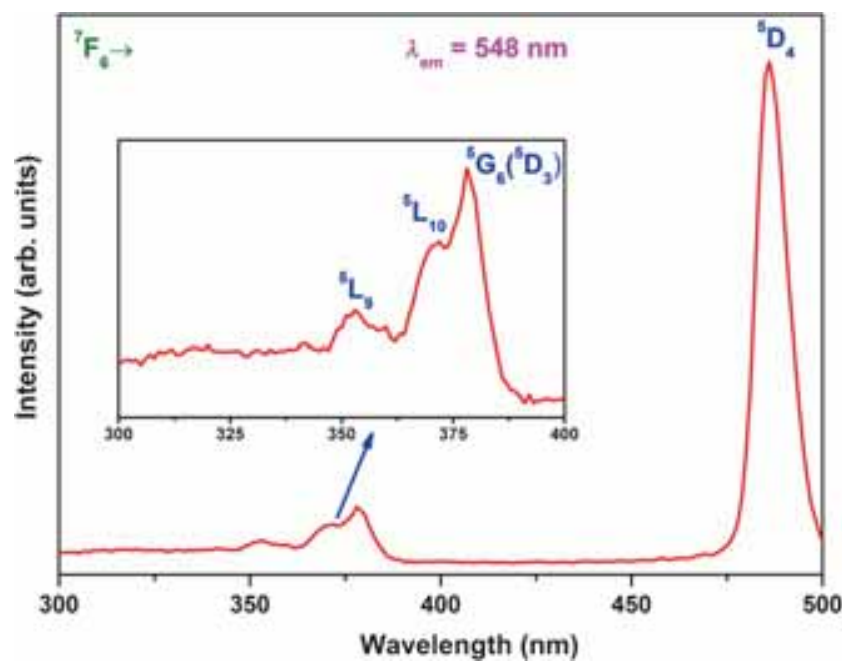

Figure 3. Excitation spectrum of $1.0 \mathrm{~mol} \% \mathrm{~Tb}^{3+}$-doped LBZLFB glass.

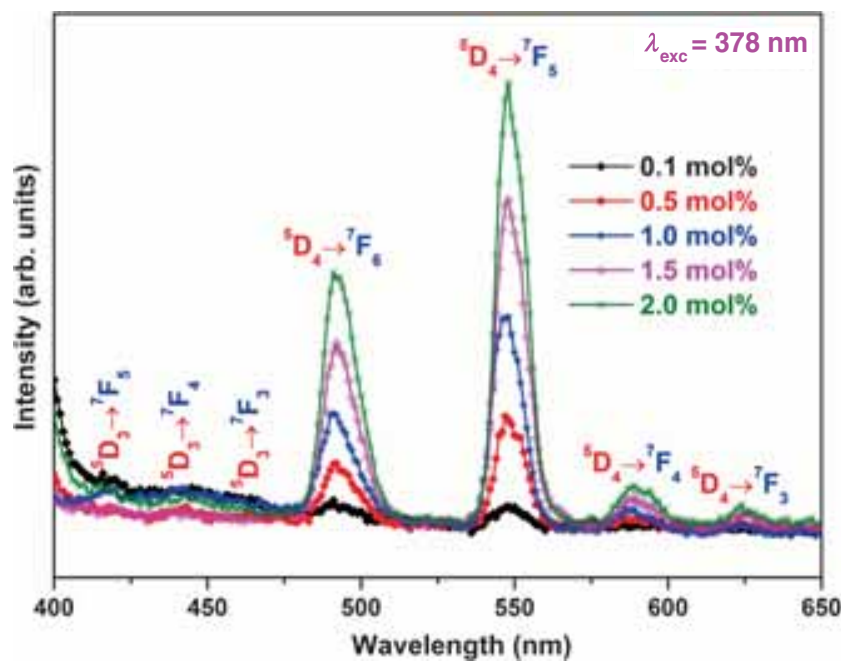

Figure 4. Fluorescence spectra of ${ }^{5} \mathrm{D}_{3}$ and ${ }^{5} \mathrm{D}_{4}$ energy levels for different concentrations of $\mathrm{Tb}^{3+}$-doped LBZLFB glasses. 
possess higher intensity. All these emission transitions are clearly described in the partial energy level diagram, shown in figure 5.

In the present investigation, the $\mathrm{Tb}^{3+}$ ion exhibit abnormal spectroscopic behaviour with concentration in the emission from ${ }^{5} \mathrm{D}_{3}$ and ${ }^{5} \mathrm{D}_{4}$ emission states. The emission transition that originates from ${ }^{5} \mathrm{D}_{3}$ excited state show fluorescence quenching at higher $\mathrm{Tb}^{3+}$ concentrations ( $\left.>1.0 \mathrm{~mol} \%\right)$. The intensity of transitions originating from the ${ }^{5} \mathrm{D}_{3}$ state increases with the increase of $\mathrm{Tb}^{3+}$ concentration up to $1.0 \mathrm{~mol} \%$ and then beyond $1.0 \mathrm{~mol} \%$, their intensity decreases. However, the fluorescence intensity of emission transitions originating from the ${ }^{5} \mathrm{D}_{4}$ level to its lower lying levels increases with the increase of $\mathrm{Tb}^{3+}$ ion concentration.

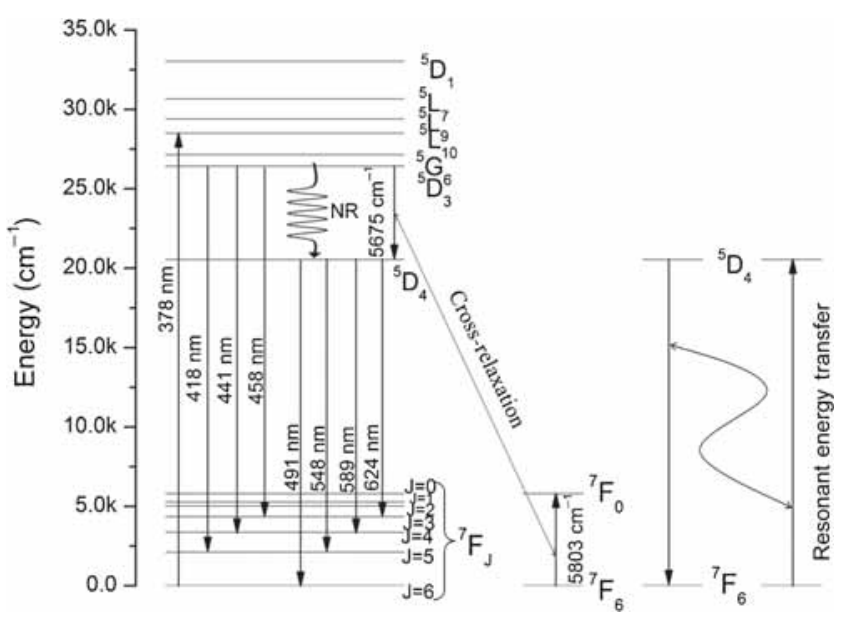

Figure 5. Partial energy level diagram showing the emission channels, cross-relaxation and resonance energy transfer in $\mathrm{Tb}^{3+}$ ions-doped LBZLFB glass.
The quenching of the ${ }^{5} \mathrm{D}_{3}$ emission and an enhancement of ${ }^{5} \mathrm{D}_{4}$ emission in the $\mathrm{Tb}^{3+}$-doped present glasses could be described by cross relaxation by resonant energy transfer. The fluorescence quenching of ${ }^{5} \mathrm{D}_{3}$ emission transitions is due to the energy transfer through cross-relaxation between $\left[{ }^{5} \mathrm{D}_{3},{ }^{7} \mathrm{~F}_{6}\right] \rightarrow\left[{ }^{5} \mathrm{D}_{4},{ }^{7} \mathrm{~F}_{0}\right]$ transition. This crossrelaxation is due to the energy transfer from ${ }^{5} \mathrm{D}_{3}$ excited state to the nearby $\mathrm{Tb}^{3+}$ ions in ${ }^{7} \mathrm{~F}_{6}$ ground state. This transfer of cross-relaxation occurs through ${ }^{5} \mathrm{D}_{3} \rightarrow{ }^{5} \mathrm{D}_{4}$ transition in one ion and ${ }^{7} \mathrm{~F}_{6} \rightarrow{ }^{7} \mathrm{~F}_{0}$ transition on the other. After that both ions quickly decay non-radiatively to the ground level. The energy resonance of these transitions can be seen in figure 5. The small energy gap $\left(5675 \mathrm{~cm}^{-1}\right)$ between the ${ }^{5} \mathrm{D}_{3}$ and ${ }^{5} \mathrm{D}_{4}$ emission levels and cross-relaxation quenching of emission derived from ${ }^{5} \mathrm{D}_{3}$ level result in the rapid population of the ${ }^{5} \mathrm{D}_{4}$ level at the expose of ${ }^{5} \mathrm{D}_{3}$ [22,23] causes a fast non-radiative decay and enhances the population of ${ }^{5} \mathrm{D}_{4}$ level much more at higher $\mathrm{Tb}^{3+}$ ion concentrations, resulting the enhancement of fluorescence intensity with the increase of $\mathrm{Tb}^{3+}$ ion concentration. Therefore, the quenching of ${ }^{5} \mathrm{D}_{3}$ emission is only responsible for the enhancement of ${ }^{5} \mathrm{D}_{4}$ emission intensity at higher $\mathrm{Tb}^{3+}$ ion concentrations. The variation of emission intensity of ${ }^{5} \mathrm{D}_{3} \rightarrow{ }^{7} \mathrm{~F}_{5}$ and ${ }^{5} \mathrm{D}_{4} \rightarrow{ }^{7} \mathrm{~F}_{5}$ transitions with $\mathrm{Tb}^{3+}$ concentration is shown in figure 6 . The fluorescence intensity of blue $\left({ }^{5} \mathrm{D}_{3} \rightarrow{ }^{7} \mathrm{~F}_{5}\right)$ and green $\left({ }^{5} \mathrm{D}_{4}\right.$ $\rightarrow{ }^{7} \mathrm{~F}_{5}$ ) emissions signify that the optimum concentration of $\mathrm{Tb}^{3+}$ ions for efficient display devices and green fibre laser is $1.0 \mathrm{~mol} \%$ in LBZLFB glasses. From the literature [24], it is noticed that when the $\mathrm{Tb}^{3+}$ ions are incorporated in pairs or clusters, no blue emission is observed. The existence of blue emission indicates the uniform distributions of $\mathrm{Tb}^{3+}$ ions in the present glass host. Thus, the studied glasses are suitable candidates to produce intense green emission.

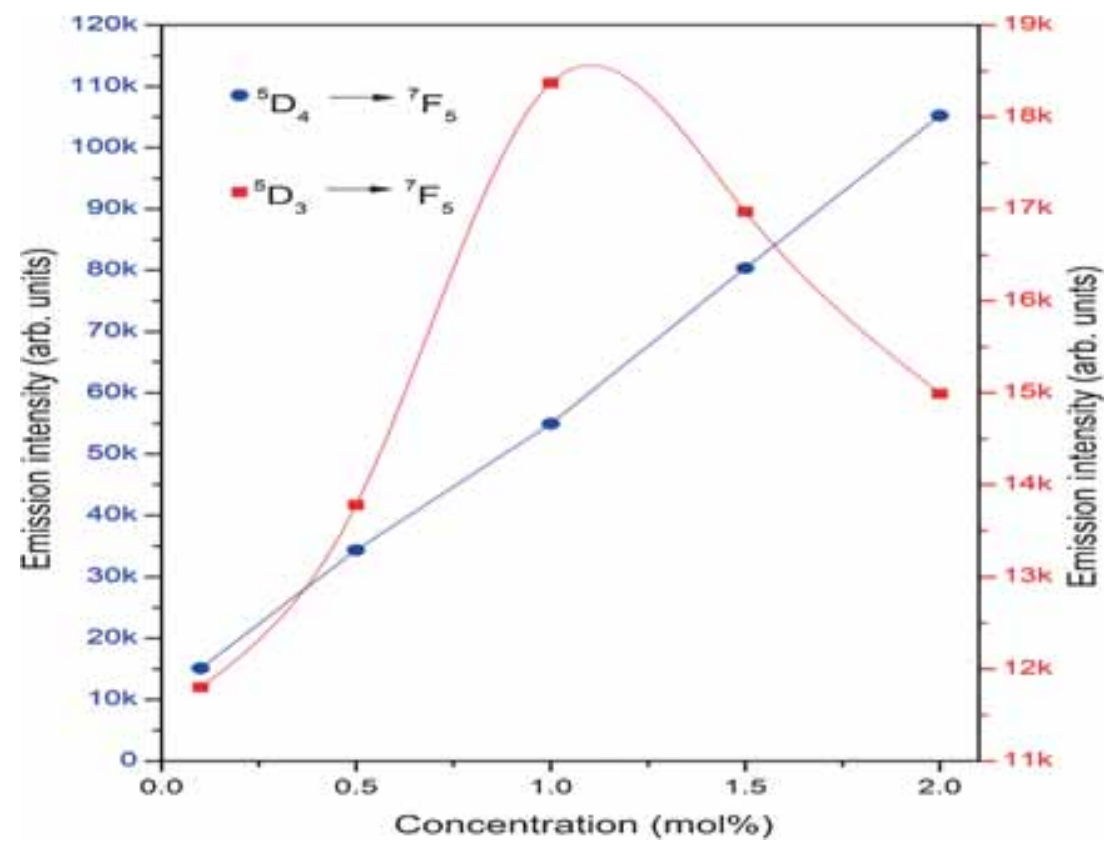

Figure 6. Variation of blue $\left({ }^{5} \mathrm{D}_{3} \rightarrow{ }^{7} \mathrm{~F}_{5}\right)$ and green $\left({ }^{5} \mathrm{D}_{4} \rightarrow{ }^{7} \mathrm{~F}_{5}\right)$ emission intensity as a function of $\mathrm{Tb}^{3+}$ ion concentration in LBZLFB glasses. 
Table 4. Radiative properties of ${ }^{5} \mathrm{D}_{4} \rightarrow{ }^{7} \mathrm{~F}_{5}$ emission transition in $1.0 \mathrm{~mol} \% \mathrm{~Tb}^{3+}$-doped LBZLFB glass.

\begin{tabular}{lllll}
\hline & \multicolumn{4}{c}{${ }^{5} \mathrm{D}_{4}$} \\
\cline { 2 - 5 } Radiative properties & ${ }^{7} \mathrm{~F}_{6}$ & ${ }^{7} \mathrm{~F}_{5}$ & ${ }^{7} \mathrm{~F}_{4}$ & ${ }^{7} \mathrm{~F}_{3}$ \\
\hline Peak emission wavelength $\left(\lambda_{\mathrm{p}}, \mathrm{nm}\right)$ & 491 & 548 & 589 & 624 \\
Effective linewidth $\left(\Delta \lambda_{\mathrm{p}}, \mathrm{nm}\right)$ & 13.26 & 11.83 & 10.92 & 8.16 \\
Radiative transition probability $\left(A_{\mathrm{R}}, \mathrm{s}^{-1}\right)$ & 58 & 440 & 19 & 50 \\
Radiative branching ratio $\left(\beta_{\mathrm{R}}\right)$ & 0.1 & 0.78 & 0.03 & 0.09 \\
Experimental branching ratio $\left(\beta_{\mathrm{m}}\right)$ & 0.32 & 0.60 & 0.06 & 0.02 \\
Stimulated emission cross-section $\left(\sigma_{\mathrm{e}} \times 10^{-22} \mathrm{~cm}^{2}\right)$ & 1.35 & 17.83 & 1.11 & 4.94 \\
Gain bandwidth $\left(\sigma_{\mathrm{e}} \times \Delta \lambda_{\mathrm{p}}, 10^{-28} \mathrm{~cm}^{3}\right)$ & 1.79 & 21.1 & 1.2 & 4.03 \\
Optical gain parameter $\left(\sigma_{\mathrm{e}} \times \tau_{\mathrm{m}}, 10^{-25} \mathrm{~cm}^{2} \mathrm{~s}\right)$ & 2.4 & 31.4 & 1.95 & 8.7 \\
Radiative lifetime $\left(\tau_{\mathrm{R}}, \mu \mathrm{s}\right)$ & & & 1.76 & \\
\hline
\end{tabular}

Table 5. Variation of lifetime $\left(\tau_{\mathrm{m}}, \mathrm{ms}\right)$, quantum efficiency $(\eta, \%)$ and energy transfer rate $\left(W_{\mathrm{NR}}, \mathrm{s}^{-1}\right)$ with respect to concentration $(\mathrm{mol} \%)$ of $\mathrm{Tb}^{3+}$ ions in LBZLFB glasses.

\begin{tabular}{lccr}
\hline Concentration & Lifetime & $\eta$ & $W_{\mathrm{NR}}$ \\
\hline 0.1 & 1.69 & 96 & 73 \\
0.5 & 1.44 & 82 & 126 \\
1.0 & 1.37 & 78 & 162 \\
1.5 & 1.16 & 66 & 294 \\
2.0 & 1.02 & 58 & 412 \\
\hline
\end{tabular}

\subsection{Radiative properties}

The J-O intensity parameters $\left(\Omega_{\lambda}\right)$ have been used to compute the radiative properties of emission characteristics for ${ }^{5} \mathrm{D}_{4} \rightarrow{ }^{7} \mathrm{~F}_{5}$ transition of the $\mathrm{Tb}^{3+}$-doped LBZLFB glasses and presented in table 4 . The radiative properties of $\mathrm{Tb}^{3+}$ ions depend on the number of factors such as property of network former and modifier of glass. The branching ratio of the fluorescent transitions characterizes the lasing power of the potential laser transition and it characterizes the possibility of attaining stimulated emission of any specific transition and is significant parameter for laser designer. An efficient laser transition has a branching ratio $\geq 0.50$. Among the observed emission transitions of $1.0 \mathrm{~mol} \% \mathrm{~Tb}^{3+}$-doped LBZLFB glass the experimental branching ratio of ${ }^{5} \mathrm{D}_{4} \rightarrow$ ${ }^{7} \mathrm{~F}_{5}$ transition is found to be 0.6 and this transition may therefore be considered as an effective laser transition suggesting its suitability for green colour display devices and to design a fibre laser. To investigate the possibility of laser emission through the ${ }^{5} \mathrm{D}_{4} \rightarrow{ }^{7} \mathrm{~F}_{5}$ transition, the stimulated emission cross section $\left(\sigma_{\mathrm{e}}\right)$, gain band width parameter $\left(\sigma_{\mathrm{e}} \times \Delta \lambda_{\mathrm{p}}\right)$ are obtained from the full-width at half maximum $\left(\Delta \lambda_{\mathrm{p}}\right)$ and optical gain parameter $\left(\sigma_{\mathrm{e}} \times \tau_{\mathrm{m}}\right)$ are determined for all the intense transitions originating from ${ }^{5} \mathrm{D}_{4}$ metastable state and listed in table 5. From the table, it is observed that the values of $\sigma_{\mathrm{e}}, \sigma_{\mathrm{e}} \times \Delta \lambda_{\mathrm{p}}$ are maximum for ${ }^{5} \mathrm{D}_{4} \rightarrow$ ${ }^{7} \mathrm{~F}_{5}$ transition. Based on the reasonably high branching ratio and laser characteristic parameters, when compared with the

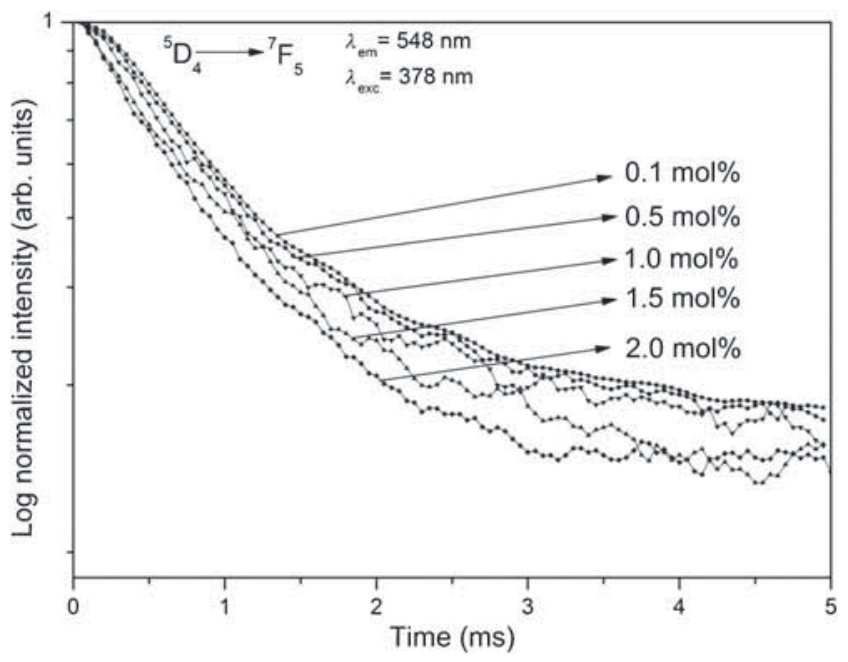

Figure 7. Decay curves of ${ }^{5} \mathrm{D}_{4} \rightarrow{ }^{7} \mathrm{~F}_{5}$ emission transition in $\mathrm{Tb}^{3+}$-doped LBZLFB glasses.

other hosts $[16,19,25,26]$, we suggest that $1.0 \mathrm{~mol} \% \mathrm{~Tb}^{3+}$ -doped LBZLFB glass has the potential candidate to produce intense green laser at $548 \mathrm{~nm}$ through the ${ }^{5} \mathrm{D}_{4} \rightarrow{ }^{7} \mathrm{~F}_{5}$ transition.

\subsection{Decay curve analysis}

The decay curves of the ${ }^{5} \mathrm{D}_{4}$ emission level of $\mathrm{Tb}^{3+}$ ions in LBZLFB glasses were recorded by monitoring the emission and excitation wavelength at 548 and $378 \mathrm{~nm}$, respectively, and shown in figure 7 . The analysis of fluorescence decay provides information regarding the energy transfer mechanism and fluorescence quenching of $\mathrm{Tb}^{3+}$ ions in LBZLFB glass host. At lower $\mathrm{Tb}^{3+}$ concentrations $(\leq 0.5 \mathrm{~mol} \%)$, the decay curves are well fitted to a single exponential function. However, at higher $\mathrm{Tb}^{3+}$ concentrations $(\geq 1.0 \mathrm{~mol} \%)$, the decay profiles exhibited non-exponential behaviour due to resonant energy transfer among the excited $\mathrm{Tb}^{3+}$ ions through $\left[{ }^{5} \mathrm{D}_{4},{ }^{7} \mathrm{~F}_{6}\right] \rightarrow\left[{ }^{7} \mathrm{~F}_{6},{ }^{5} \mathrm{D}_{4}\right]$ transitions (figure 5). The experimental lifetime $\left(\tau_{\mathrm{m}}\right)$ of ${ }^{5} \mathrm{D}_{4}$ level determined by taking 


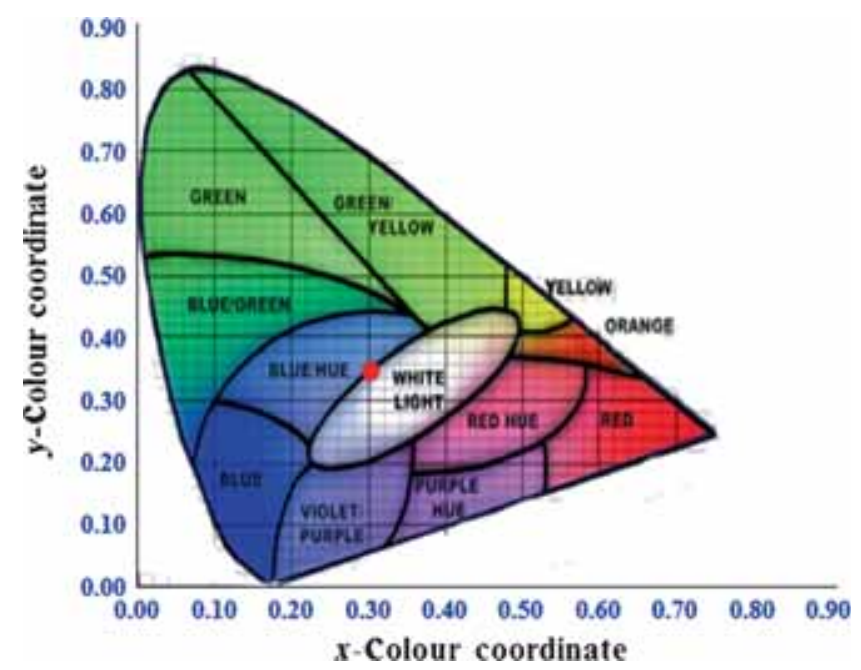

Figure 8. CIE chromaticity diagram of $1.0 \mathrm{~mol} \% \mathrm{~Tb}^{3+}$-doped LBZLFB glass.

the first e-folding times of the decay curves of $\mathrm{Tb}^{3+}$ ions are $1.69,1.44,1.37,1.16$ and $1.02 \mathrm{~ms}$ for $0.1,0.5,1.0,1.5$ and $2.0 \mathrm{~mol} \%$ of $\mathrm{Tb}^{3+}$ ion concentration, respectively. However, the radiative decay $\left(\tau_{R}\right)$ is calculated as $1.76 \mathrm{~ms}$ by applying the $\mathrm{J}-\mathrm{O}$ theory. The difference between $\tau_{\mathrm{m}}$ and $\tau_{\mathrm{R}}$ may be due to the non-radiative contributions from the ${ }^{5} \mathrm{D}_{4}$ level of $\mathrm{Tb}^{3+}$ ions in LBZLFB glasses.

For photonic applications like fibre lasers and planar waveguides, the fluorescence quantum efficiency $(\eta)$ is an important parameter controlling the performance of the material. For $1.0 \mathrm{~mol} \% \mathrm{~Tb}^{3+}$ ions-doped LBZLFB glass, the value of quantum efficiency $\eta=\tau_{\mathrm{m}} / \tau_{\mathrm{R}} \times 100 \%$ is found to be $78 \%$. It is found that higher than that of $1.0 \mathrm{~mol} \% \mathrm{~Tb}^{3+}$ -doped LCZSFB [13] glass. Further, the experimental decay time can be written as

$$
\frac{1}{\tau_{\mathrm{m}}}=\frac{1}{\tau_{\mathrm{R}}}+W_{\mathrm{MPR}}+W_{\mathrm{ET}},
$$

where $W_{\mathrm{MPR}}$ and $W_{\mathrm{ET}}$ represent the multi phonon relaxation rate and the rate of energy transfer, respectively. The energy gap of $\sim 14,750 \mathrm{~cm}^{-1}$ between the ${ }^{5} \mathrm{D}_{4}$ emission state and the ${ }^{7} \mathrm{~F}_{0}$ lower lying state, suppress the multi phonon relaxation rates in the LBZLFB glass system. Thus, the energy transfer is mainly due to resonant energy transfer and the rate of energy transfer

$$
W_{\mathrm{ET}}=\frac{1}{\tau_{\mathrm{m}}}-\frac{1}{\tau_{\mathrm{R}}} \mathrm{s}^{-1}
$$

For $1.0 \mathrm{~mol} \% \mathrm{~Tb}^{3+}$ ions-doped LBZLFB glass, the energy transfer rate $W_{\mathrm{ET}}$ is found to be $162 \mathrm{~s}^{-1}$ and is found lower than those reported for LCZSFB glass [13].

\subsection{Chromaticity coordinates}

To recognize the emission colour of the prepared glasses, the CIE 1931 chromaticity coordinates were calculated by using CIE calculation software. A typical CIE values of $1.0 \mathrm{~mol} \% \mathrm{~Tb}^{3+}$ ions-doped LBZLFB glasses are shown in CIE diagram, figure 8 . As indicated in the figure, the CIE values $(0.303,0.350)$ are located in near white light region. However, the emission of $\mathrm{Tb}^{3+}$-doped LBZLFB glasses are showing predominant at $550 \mathrm{~nm}$ (green colour) as represented in figure 4. This suggests that the obtained values are slightly deviated from the pure white colour source chromaticity values $(0.33,0.33)$.

\section{Conclusions}

In summary, we reported transparent LBZLFB glasses with different $\mathrm{Tb}^{3+}$ concentrations, prepared by melt quenching method. A quenching in fluorescence intensity of ${ }^{5} \mathrm{D}_{3}$ state is observed beyond $1.0 \mathrm{~mol} \% \mathrm{~Tb}^{3+}$ and is attributed to the energy transfer through cross-relaxation of $\left[{ }^{5} \mathrm{D}_{3},{ }^{7} \mathrm{~F}_{6}\right]$ $\rightarrow\left[{ }^{5} \mathrm{D}_{4},{ }^{7} \mathrm{~F}_{0}\right]$ transitions. The fluorescence intensity of ${ }^{5} \mathrm{D}_{4}$ emission state is increased with increase of $\mathrm{Tb}^{3+}$ concentration due to fast non-radiative decay from ${ }^{5} \mathrm{D}_{3}$ to ${ }^{5} \mathrm{D}_{4}$ levels. The decrease of experimental decay times with increase of $\mathrm{Tb}^{3+}$ concentration is attributed to the resonant energy transfer through $\left[{ }^{5} \mathrm{D}_{4},{ }^{7} \mathrm{~F}_{6}\right] \rightarrow\left[{ }^{7} \mathrm{~F}_{6},{ }^{5} \mathrm{D}_{4}\right]$ emission channels. The radiative properties of $1.0 \mathrm{~mol} \% \mathrm{~Tb}^{3+}$ ions-doped LBZLFB glasses strongly suggest their utility in the development of green colour display devices and fibre lasers.

\section{Acknowledgements}

BDPR is thankful to the Department of Atomic Energy-Board of Research in Nuclear Sciences (DAE-BRNS), Government of India, INDIA, for providing financial assistance to carry out this work; vide reference number: 34/14/06/2014; dated: 21-04-2014. We also acknowledge the Sophisticated Analytical Instrument Facility (SAIF), Indian Institute of Technology, Chennai, for extending instrumental facilities.

\section{References}

[1] Tanimeera K, Shinn M D, Silbley W A, Drexhage M G and Brown R N 1984 Phys. Rev. B 302429

[2] Judd B R 1962 Phys. Rev. 127750

[3] Ofelt G S 1962 J. Chem. Phys. 37511

[4] Qin G, Yamashita T and Ohishi Y 2007 Eletron. Lett. 43377

[5] Allain Y, Monerie M and Poignant H 1992 Electron. Lett. 28 111

[6] McAvoy N and Filipescu N 1967 Appl. Phys. Lett. 10160

[7] Fujimoto Y, Ishii O and Yamazaki M 2010 Electron. Lett. 46 1285

[8] Yamashita T and Ohisi Y 2007 Jpn. J. Appl. Phys. 461991

[9] Carnall W T, Fields P R and Rajnak K 1968 J. Chem. Phys. 494447

[10] Madhukar Reddy C, Dillip G R, Mallikarjuna K, Zulifiqar Ali Ahamed Sd, Sudhakar Reddy B and Deva Prasad Raju B 2011 J. Lumin. 1311368 
[11] Nageswara Raju C, Adinarayana Reddy C, Sailaja S, Seo Hyo Jin and Sudhakar Reddy B 2012 J. Mater. Sci. 47772

[12] Deva Prasad Raju B and Madhukar Reddy C 2012 Opt. Mater. 341251

[13] Madhukar Reddy C, Sudhakar Reddy B, Dillip G R, Mallikarjuna K and Deva Prasad Raju B 2012 J. Mol. Struct. 1019166

[14] Jorgensen C K and Reisfeld R 1983 J. Less-Common. Met. 93 107

[15] Kadono K, Yazawa T, Shojiya M and Kawamoto K $2000 \mathrm{~J}$. Non-Cryst. Solids 27475

[16] Abdul Azeem P, Kalidasan M, Reddy R R and Ramagopal K 2012 Opt. Commun. 2853787

[17] Takabe H, Nageno Y and Morinaga K 1994 J. Am. Chem. Soc. 772132
[18] Amarnath G and Buddhudu S 1990 J. Non-Cryst. Solids 122 66

[19] Sagar P K D, Kistaiah P, Rao B A, Reddy C V V, Moorthy K S N and Veeraiah N 1999 J. Mater. Sci. Lett. 1855

[20] Carnall W T, Hessler J P and Wagner F 1978 J. Phys. Chem. 822152

[21] Rai S and Bokatial L 2011 Bull. Mater. Sci. 34227

[22] Chang Y S, Liu H J, Li Y C, Chai Y L and Tsai Y Y 2007 J. Solid State Chem. 1803076

[23] Kao F S and Chen T M 2002 J. Lumin. 96261

[24] Lammers M J J and Blassae G 1986 Chem. Phys. Lett. 126 405

[25] Prasad S V G V A, Srinivasa Reddy M, Ravi Kumar V and Veeraiah N 2007 J. Lumin. 127637

[26] Rai S and Hazarika S 2008 Opt. Mater. 301343 